\title{
EPIDURAL ANESTHESIA FOR CESAREAN SECTION IN ATRIAL SEPTAL DEFECT WITH PULMONARY HYPERTENSION
}

Rashmi Bengali ${ }^{1}$

\section{HOW TO CITE THIS ARTICLE:}

Rashmi Bengali. "Epidural Anesthesia for Cesarean Section in Atrial Septal Defect with Pulmonary Hypertension". Journal of Evolution of Medical and Dental Sciences 2015; Vol. 4, Issue 57, July 16;

Page: 10007-10009, DOI: 10.14260/jemds/2015/1446

ABSTRACT: Pregnant patients with atrial septal defect (ASD) with pulmonary hypertension, occasionally present for anaesthesia. These patients are considered high risk for anaesthesia due to increased chances of perioperative cardiovascular complications. Anaesthesia requires intensive cardiovascular monitoring and maintenance of stable pulmonary and systemic haemodynamics. Here is a case of second gravida for LSCS which was managed under epidural anaesthesia successfully.

KEYWORDS: Atrial septal defect, Pulmonary hypertension, Caesarean section, Epidural anaesthesia.

INTRODUCTION: Various cardiac diseases can complicate the normal course of pregnancy. Though the incidence varies from 1-4\%, whenever the heart fails to meet the dynamic physiological changes required during pregnancy, the cardiac instability results. Among the common congenital acynotic heart diseases, ASDs are anatomically classified into four types: 1) Ostium secundum (85\%), 2) Ostium primum (10\%), 3) Sinus venosus (5\%), and 4) Coronary sinus defects (rare). ${ }^{1}$ Left to right intra-cardiac shunt leading to right ventricular volume overload causes increase in pulmonary blood flow and pulmonary hypertension. It results into right ventricular hypertrophy and congestive heart failure. Here is a case of osteum secundum defect with pulmonary hypertension who underwent emergency LSCS under epidural anaesthesia successfully.

CASE REPORT: A 24 yrs unbooked thin built second gravida with 37 weeks of gestation was posted for emergency LSCS in view of cephalo pelvic disproportion (CPD) and failure to progress. She had one abortion previously. She had history of breathlessness and palpitations at $7^{\text {th }}$ month of gestation. She was investigated and her 2D Echo revealed E/o 24mm ostium secundum atrial septal defect with left to right shunt and grade I tricuspid regurgitation. She had pulmonary hypertension of PASP of $45 \mathrm{~mm}$. Ejection fraction was 55\%. There was E/o minimum pericardial effusion. She was treated medically but patient did not continue the treatment nor follow up. This time she had no such complaints of breathlessness, palpitations or chest pain.

Her exercise tolerance was good. Her pulse rate was $82 / \mathrm{min}$. BP was $114 / 70 \mathrm{mmHg}$, Spo 2 was $90 \%$ on air, bilateral pitting pedal edema was present. The respiratory rate was $22 / \mathrm{min}$, NYHA class I. Chest was clear on auscultation. There was no evidence showing pericardial effusion. No clubbing or cyanosis. The ECG showed sinus rhythm with right axis deviation. She had systolic murmur in tricuspid area with loud $S_{2}$. Rest of the physical examination was unremarkable. Her biochemical, haematological and blood coagulation tests were within normal limits. Patient was not nil by mouth. Patient was explained about the poor outcome of delivery and informed consent was obtained. Antiemetic prophylaxis was given with IV 50mg Ranitidine and 4mg Ondensetron. Multipara monitor with pulse rate, NIBP, Spo2, ECG was applied. IV Ringer lactate was started. IV 2gm Ampicillin was given. Lumbar epidural analgesia was administered without any difficulty in L2-3 inter space; with patient in left lateral position, and test dose of $2 \mathrm{ml}$ of inj. lignocaine $2 \%$ was given. Anaesthesia was 
instituted slowly with incremental doses up to $10 \mathrm{ml}$ of $0.5 \%$ Ropivacaine being more cardiostable. $\mathrm{O}_{2}$ supplimentation was started on mask. The sensory block spread up to T8 level within 8 min. Except for one brief episode of systemic hypotension $(80 / 60 \mathrm{mmHg})$, which was treated with inj. Ephedrine $10 \mathrm{mg}$, the intra operative course was uneventful.

A wedge was put below right buttock. A baby weighing $2.6 \mathrm{~kg}$ was delivered with APGAR score of 6 and 9 at 1 and $5 \mathrm{~min}$. Patient was started with IV Oxytocine 20 units in a drip. Postoperatively patient was continued on supplemental $\mathrm{O}_{2} 4 \mathrm{~L} / \mathrm{min}$ through mask for next $12 \mathrm{hrs}$ even as SpO2 remained at 94-96\%. Epidural Postoperative analgesia was administered epidurally with inj. Tramadol $75 \mathrm{mg}$. Patient was shifted to recovery room and next day to ward. Postoperative period was uneventful and patient was discharged for cardiologist reference on $12^{\text {th }}$ day.

DISCUSSION: Mean pulmonary artery pressure of $>25 \mathrm{mmHg}$ at rest or $>30 \mathrm{mmHg}$ on exercise is generally considered as the diagnostic criteria for pulmonary hypertension. It excludes the congenital heart disease, myocardial disease or valvular disease etc. The enhanced activity of thromboxane or diminished activity of prostacyclin or impaired synthesis of nitric oxide has also been associated with PPH. ${ }^{2}$ Pulmonary hypertension in pregnant women though uncommon carry high mortality and death regardless of severity of disease. Hence pregnancy has been suggested to be the contraindication in pulmonary hypertension. ${ }^{3}$

The hormonal changes associated with pregnancy allow large amount of fluid to accumulate in the interstitial space. Following delivery, this fluid is suddenly shifted to maternal circulation, increasing preload significantly and further increasing pulmonary hypertension. This lethal risk is highest during first 10 days of post-partum period. In healthy pregnant woman PVR is $34 \%$ less than in non-pregnant states, as the prostacyclin production is increased fivefold. The withdrawal of this pulmonary vasodilator effect of prostacyclin in immediate post-partum period may account for majority of deaths. ${ }^{4}$

Normal Vaginal delivery can lead to increased mortality in early post-partum period, hence Johnson et al advocated elective caesarean section to prevent haemodynamic changes of labour and to spare fetus as well as the risk of hypoxaemia secondary to maternal physical exertion. ${ }^{5}$ With careful epidural analgesia vaginal delivery can be successful, hence LSCS can be restricted to obstetric indications only. ${ }^{6}$ In our case emergency LSCS was planned due to failure to progress.

The management of anaesthesia in such patients differs with different school of thoughts. The goals of management should include-avoiding increase in pulmonary vascular resistance (PVR), avoid decrease in venous return (VR) and reduction in systemic vascular resistance (SVR) and avoid myocardial depression. Though general anaesthesia is recommended for LSCS, maternal myocardial depression, neonatal depression, sudden cardiovascular collapse, increase in PVR due to Nitrous oxide, inadequate analgesia are some of the disadvantages. ${ }^{7}$

If preload and after load are well maintained, regional blocks can be given. ${ }^{3}$ Epidural analgesia not only avoids increase in PVR, it provides optimal analgesia in combination with controlled vasodilatation to accommodate autotransfusion. ${ }^{8}$ Considering all above factors we successfully managed the case with epidural anaesthesia. Post-operative analgesia was provided with Tramadol given through the epidural catheter which provided stable cardiovascular situation. 
CONCLUSION: We experienced successful outcome with epidural block was experienced in this case. However no definite conclusion can be drawn from the single case and one should tailor the anaesthesia technique to avoid increase in PVR, decrease in SVR, hypotension and hypoxia with meticulous intraoperative and postoperative monitoring. It is demonstrated that in selected cases, caesarean section can be performed under epidural anesthesia. The peripartum management of patients with ASD is best conducted by a multidisciplinary approach to provide better results.

\section{REFERENCES:}

1. Harrison principles of internal medicine, $17^{\text {th }}$ edition. 1459 .

2. Lewis J. Rubin. Primary Pulmonary Hypertension. NEJM 1997; 336: 111-117.

3. Smedstad KG, Cramb R, Morrison Dh. Pulmonary hypertension and pregnancy: a series of eight cases. Can J. Anaesth 1994; 41:502-12.

4. Khan MJ, Bhatt SB, Krye JJ. Anesthetic consideration for parturient with Primary Pulmonary Hypertension, review of literature and clinical presentation. International J of Obst. Anesthesia 1996; 5: 36-42.

5. Johnson Md, Saltzman DH. Anaesthetic and obstetric management of high risk pregnancy. St. Louis Mosby-year book, Inc1991; 237:245-51.

6. Roessler P, Lamberet TF. Anaesthesia for caesarean section in the presence of primary pulmonary hypertension. Anaesth Intensive care 1986; 14:317-20.

7. Atanassoff P, Alon E, Schmid ER. Epidural anaesthesia for caesarean section in a patient with severe pulmonary hypertension. Acta Anaesth Scand 1989; 33:75-77.

8. Power KJ, Avery AF. Extra duralanalgesiain the intrapartum management of a patient with pulmonary hypertension. Br J Anaesth 1989; 63:116-20.

\section{AUTHORS:}

1. Rashmi Bengali

\section{PARTICULARS OF CONTRIBUTORS:}

1. Associate Professor, Department of Anaesthesia, Government Medical College, Aurangabad.

FINANCIAL OR OTHER COMPETING INTERESTS: None
NAME ADDRESS EMAIL ID OF THE CORRESPONDING AUTHOR:

Dr. Rashmi Bengali, C-19 Town Centre, Cidco, Aurangabad.

E-mail: drrvbengali@gmail.com

Date of Submission: 16/06/2015. Date of Peer Review: 17/06/2015. Date of Acceptance: 09/07/2015. Date of Publishing: 16/07/2015. 